\title{
THE STUDY OF CHOLECYSTECTOMY (OPEN? LAP) IN ACUTE CALCULOUS CHOLECYSTITIS
}

\author{
Ananda B. $B^{1}$, Ramesh B. S2, Sai Kumar H. R3 , Safarulla S. $H^{4}$, Mallipeddi Parthasri ${ }^{5}$ \\ ${ }^{1}$ Associate Professor, Department of General Surgery, Dr. B. R. Ambedkar Medical College and Hospital. \\ 2 Professor \& HOD, Department of General Surgery, Dr. B. R. Ambedkar Medical College and Hospital \\ ${ }^{3}$ Assistant Professor, Department of General Surgery, Dr. B. R. Ambedkar Medical College and Hospital. \\ ${ }^{4}$ Consultant Surgeon, Muthoot Healthcare, Kozhencherry, Kerala. \\ ${ }^{5}$ Postgraduate Student, Department of General Surgery, Dr. B. R. Ambedkar Medical College and Hospital.
}

\section{ABSTRACT}

\section{BACKGROUND}

Gallstone is the most common biliary pathology. Optimal surgical timing and operative technique in the treatment of acute cholecystitis are of major importance. We intend with this study to clarify further the timing of surgery for acute calculous cholecystitis, its complications, the cause and rate of conversion to open cholecystectomy.

\section{MATERIALS AND METHODS}

The study was conducted at our hospital from Oct 2012 to November 2014. A total of 55 patients diagnosed with acute calculous cholecystitis were studied for outcome with timing of surgery, conversion rates to open and complications.

\section{RESULTS}

None of the patients who underwent early intervention required conversion to open. 5 patients from delayed intervention group required open conversion. Higher the age more is the incidence of conversion. Post-op infections and complications were more in open. The conversion rate was higher in the delayed intervention group. The operative time was less with open cases; however, the blood loss, hospital stay and cost were higher compared to LC.

\section{CONCLUSION}

The optimal timing of laparoscopic cholecystectomy for acute cholecystitis is within 72 hours of admission. Laparoscopic cholecystectomy is a reliable, safe modality for AC. It should be the first choice before restoring to open surgery.

\section{KEYWORDS}

Acute Cholecystitis, Gallstones, Conversion Rate, Laparoscopic Cholecystectomy, Open Cholecystectomy.

HOW TO CITE THIS ARTICLE: Ananda BB, Ramesh BS, Kumar SHR, et al. The study of cholecystectomy (Open? lap) in acute calculous cholecystitis. J. Evolution Med. Dent. Sci. 2016;5(101):7400-7404, DOI: 10.14260/jemds/2016/1675
BACKGROUND
Gallstone occurrence is one of the common disease processes treated by general surgeon. In 1882, Carl Langenbuch performed the first cholecystectomy, enunciating a principal, "the gall bladder needs to be removed not because it contains stones, but because it forms them". Over the years, cholecystectomy has been the gold standard in the treatment of gallstone disease.
It is understandable that the next logical step would be to attempt the surgical removal of gallbladder through laparoscope. Open cholecystectomy which had been
As an added bonus it has an excellent cosmetic result.
Laparoscopic Cholecystectomy further offers the long term benefit of negligible incidence of wound infection, incisional hernia, nerve entrapment and postoperative adhesions. In the field of laparoscopy, laparoscopic cholecystectomy has been the first major surgery performed and has paved path for laparoscopic intervention for other intra-abdominal pathologies. So here we are studying both the techniques and their standing in present scenario. With the background of experience in open cholecystectomy, we commenced our work on laparoscopic cholecystectomy. performed unchallenged for over a century now faces an end with advent of laparoscopic cholecystectomy. Patient acceptance, preference and demand for laparoscopic cholecystectomy is logical since this procedure gives less pain, need for less medication, far shorter hospitalisation and most important, permits an early return to family and normal work and activity.

Financial or Other, Competing Interest: None.

Submission 26-11-2016, Peer Review 09-12-2016,

Acceptance 12-12-2016, Published 15-12-2016.

Corresponding Author:

Dr. Ananda B. B,

H-No. 135,

Ganesha Layout, MS Palya,

Vidyaranyapura Post,

Bangalore-560097.

E-mail: anandabb007@gmail.com

DOI: $10.14260 /$ jemds $/ 2016 / 1675$

\section{Aims and Objectives}

1. Comparative study of the duration of surgery in both groups.

2. Comparative study of postoperative hospital stay, drugs used, time taken for return to work and study of conversion rate to open surgery.

3. Comparative study of postoperative complications, mortality and morbidity in both groups.

\section{MATERIALS AND METHODS}

The study subjects consisted of 40 patients with a diagnosis of cholelithiasis/chronic cholecystitis who underwent cholecystectomy at our institute from Oct. 2012 to November 2014. The patients were interviewed for detailed clinical history. All the patients were examined and underwent routine blood investigations with LFT and coagulation tests. Abdominal USG was performed in all the cases. 


\section{Inclusion Criteria}

Patients with cholelithiasis proven by USG with at least one attack of upper abdominal pain and considered fit for elective cholecystectomy were included in the study.

\section{Exclusion Criteria}

The patients with following conditions were excluded from the study:

- History or investigations suggesting CBD stones.

- History of prior abdominal surgery.

- Patient's age above 70 years.

Written informed consent was obtained from all the patients before their enrolment in the study. The study protocol was approved by the local ethical committee of this hospital. Patients were randomly distributed into two groups of (laparoscopic cholecystectomy and open cholecystectomy). One group was subjected to laparoscopic cholecystectomy and the other to open cholecystectomy. All patients were kept nil by mouth overnight prior to surgery and received antibiotic prophylaxis. Nasogastric tube was inserted depending on individual basis and all patients were asked to empty the bladder prior to entering the operation theatre.

\section{Surgical Procedure}

All operations were performed by the same consultant surgeon. All operations were done under General Anaesthesia.

\section{Open Cholecystectomy}

A subcostal muscle transection incision is used for open cholecystectomy; the length of the incision is tailored to the individual patient and kept to the minimum necessary to allow safe and adequate access to the gall bladder.

Dissection is started at Calot's triangle and proceeded antegrade towards the fundus. Fundus first method is used in case of dense adhesions where anatomy of Calot's triangle is not clear.

\section{Laparoscopic Cholecystectomy}

Laparoscopic Cholecystectomy is performed with the operating surgeon on the left side of the table. Pneumoperitoneum created using Veress needle and by Hassan's technique in some cases.

It involved two $10 \mathrm{~mm}$ and two $5 \mathrm{~mm}$ trocars. Peritoneal cavity is visualised and any adhesions if present are released. Calot's triangle (Figure 1) is visualised and dissection is carried out by means of electrocautery and the cystic duct and artery (Figure 2) are secured with titanium clips. At the completion of the operation, a subhepatic drain is inserted as required in both the groups. All wounds are infiltrated with local anaesthetic. Once the patients are reversed from anaesthesia, they are shifted to recovery room for observation for an hour and then shifted to the postop ward. All patients are administered NSAIDs and anti-emetics as required. Patients are allowed liquids once bowel sounds returned. Patients are discharged from the hospital once they are fully mobilised and able to tolerate a normal diet and pain relief is adequate.

Pain in the postop period is rated by each patient using a Visual Analogue Scale (from 0 to 5).

Patients are encouraged to resume work and normal daily activity as soon as possible. Evaluation of return to normal work and postoperative complications is made during an OPD appointment, 4 weeks after surgery.
Data is collected prospectively and included patient's demographics, laboratory results, operative findings, requirement for conversion to open cholecystectomy, operating time (from incision to closure), peri-operative bleeding, operative complications, duration of postoperative pain, analgesic administration and length of hospital stay along with postoperative complications if any.

The total cost incurred during hospitalisation is recorded. The cost included the investigations costs, operation costs, medications and the postoperative period costs. The patients are also asked to grade their perception to the cosmetic results on a scale of 1 to 5 . The histopathology of the specimen is also noted.

\section{Statistical Analysis}

The Statistical software namely SPSS 15.0, MedCalc 9.0.1 are used for the analysis. Descriptive and inferential statistical analysis is done. Variables on continuous measurements are presented on Mean \pm SD (Min-Max) and variables on categorical measurements are presented in Number (\%). Significance is assessed at $5 \%$ level of significance.

Chi-square/Fisher Exact test is used to find the significance of study parameters on categorical scale between two or more groups. A P value of $<0.05$ is considered significant.

\section{RESULTS}

Patients were randomised into two groups, laparoscopic cholecystectomy group (LC) and open cholecystectomy group (OC). Each group had twenty patients. Twenty patients were randomised to each group. The median age (Table 1) of the patients was 38 (18-60) and 42(20-68) years in LC and OC group respectively. All patients in both the groups presented with pain in the right upper quadrant. The other complaints seen were fever, vomiting and dyspepsia. None of the patients had jaundice or previous history of jaundice. 8 patients in OC and 10 patients in LC group had similar history of pain abdomen in the past. All patients in both the groups underwent abdominal sonography. Most of the patients in both the group had multiple stones. 5 patients in OC group and 3 patients in LC group had peri-cholecystic fluid collection suggestive of acute cholecystitis.

All patients were operated under general anaesthesia (Table 2). The average blood loss was far less in LC group when compared to OC group. The main reason for blood loss in LC group is the slippage of the clip applied to the cystic artery and from the gall bladder bed. The median duration of operative procedure is $70 \mathrm{~min}$. for $\mathrm{OC}$ and $105 \mathrm{~min}$. for $\mathrm{LC}$. The difference was found to be significant $(\mathrm{p}=0.001)$. The more time required in LC was due to intra-operative gas leak, Calot's triangle dissection, slippage of clip and delivery of gall bladder through the port site. The main complications noted were bile leak (8 patients in LC and 4 patients in OC group) and stone spillage (3 in LC and 1 in OC). There was no instance of CBD injury in either group. Injury to liver during retraction was seen in 1 patient who underwent OC. Drains were required in 19 patients in OC group and 17 patients in LC group. In other cases, drains were not kept as the haemostasis was found to be adequate. Two patients were converted from laparoscopy to open surgery due to slippage of the clip applied to the cystic artery and dense adhesions in the Calot's triangle. The pain score based on a Visual Analogue Score (VAS) favoured laparoscopy group. 
Wound infection was more common in the OC group. One patient in OC group had wound dehiscence which was sutured later under anaesthesia. Due to this, the antibiotics (Table 3) were used for 7 days in OC group compared to 5 days in LC group. One patient who underwent OC developed incisional hernia at 6 months followup which was repaired by on lay mesh repair.

The LC group patients were started on oral feeds at an average of 9 hours (6-8 hours) while in OC group patients it took an average of 21 hours (12-36 hours). The median duration of hospital stay was 4 days (2-7 days) in LC group and 7 days (4-10 days) in OC group. It was more in OC group due to increased pain, wound infection, injectable antibiotics used and less mobilisation due to pain. All patients who underwent LC were able to return to normal work on an average of 5 days compared to 8 days in OC group. 16 patients who underwent LC felt that they had a good cosmetic end result while only 6 patients of open group had acceptable result. LC was costlier compared to the cost of the open procedure. The cost in the LC group was more due to its increased operative costs.

\section{Table 1: Pre-op findings}

\begin{tabular}{|c|c|c|c|}
\hline Variable & $\begin{array}{l}\text { Laparoscopy } \\
\text { group }\end{array}$ & Open group & P value \\
\hline Median Age (in yrs) & 38 & 42 & \\
\hline M:F & $1: 3$ & $1: 1$ & \\
\hline \multicolumn{3}{|c|}{ Presenting Complaints } & $>0.05$ \\
\hline Pain RUQ & 20 & 20 & \\
\hline Vomiting & 7 & 6 & \\
\hline Fever & 5 & 4 & \\
\hline Dyspepsia & 4 & 4 & \\
\hline Similar history & 10 & 8 & \\
\hline \multicolumn{3}{|l|}{ USG Findings } & $>0.05$ \\
\hline Solitary stone & 5 & 6 & \\
\hline Multiple stones & 15 & 14 & \\
\hline Pericholecystic fluid & 3 & 5 & \\
\hline
\end{tabular}

Table 2: Operative findings

\begin{tabular}{|c|c|c|c|}
\hline Variable & Laparoscopy group & Open group & P value \\
\hline \multicolumn{4}{|l|}{ Operative Findings } \\
\hline Operating time (in mins) & 105 & 70 & 0.001 \\
\hline Range & $(60-160)$ & $(40-135)$ & \\
\hline Blood loss & & & $>0.05$ \\
\hline$<100 \mathrm{ml}$. & 18 & 15 & \\
\hline$>100 \mathrm{ml}$. & 2 & 5 & \\
\hline Complications & & & $>0.05$ \\
\hline Bile leak & 8 & 4 & \\
\hline Stone spillage & 3 & 1 & \\
\hline CBD Injury & 0 & 0 & \\
\hline Adj. Organ injury & 1 & 1 & \\
\hline Drains used & 17 & 19 & $>0.05$ \\
\hline Conversion & 2 & -- & \\
\hline \multirow{2}{*}{\multicolumn{4}{|c|}{ Pain Score \& Medication }} \\
\hline & & & \\
\hline VAS (Grades $0-5$ ) & Grade 2 & Grade 3 & 0.024 \\
\hline Range & $0-3$ & $1-5$ & \\
\hline Duration of pain (days) & 2 & 4 & 0.001 \\
\hline Range & $1-6$ & $2-10$ & \\
\hline Analgesic used for (Days) & 3 & 5 & 0.016 \\
\hline Range & $(2-6)$ & $(2-10)$ & \\
\hline
\end{tabular}


Table 3: Post operative Details

\begin{tabular}{|c|c|c|c|}
\hline Variable & Laparoscopy group & Open group & P value \\
\hline \multicolumn{4}{|c|}{ Post operative outcome \& antibiotics } \\
\hline Wound infection & & & $>0.05$ \\
\hline Nil & 19 & 15 & \\
\hline Moderate & 1 & 3 & \\
\hline Severe & 0 & 2 & \\
\hline Duration of antibiotics used & 5 & 7 & 0.1 \\
\hline Range & $3-7$ & $5-14$ & \\
\hline & & & \\
\hline Incisional hernia & 0 & 1 & \\
\hline \multicolumn{4}{|l|}{ Post operative Recovery } \\
\hline $\begin{array}{l}\text { Time taken to retum of bowel } \\
\text { sounds (in hrs) }\end{array}$ & $9(6-12)$ & $21(12-30)$ & 0.21 \\
\hline $\begin{array}{l}\text { Time to resumption of oral } \\
\text { feeds (in hours) }\end{array}$ & $(6-18)$ & $21(12-36)$ & 0.345 \\
\hline $\begin{array}{l}\text { Duration of hospital stay ( in } \\
\text { days) }\end{array}$ & $(2-7)$ & $7(4-10)$ & 0.001 \\
\hline $\begin{array}{l}\text { Time taken to return to normal } \\
\text { work (in days) }\end{array}$ & $(3-10)$ & $8(5-14)$ & 0.018 \\
\hline \multicolumn{3}{|l|}{ Cosmesis score } & $>0.05$ \\
\hline Unacceptable & 0 & 14 & \\
\hline Acceptable & 4 & 6 & \\
\hline Good & 16 & 0 & \\
\hline \multicolumn{3}{|l|}{ Cost Analysis } & $>0.05$ \\
\hline$<3000$ & 2 & 8 & \\
\hline$<3000-6000$ & 14 & 8 & \\
\hline$>6000$ & 4 & 4 & \\
\hline
\end{tabular}

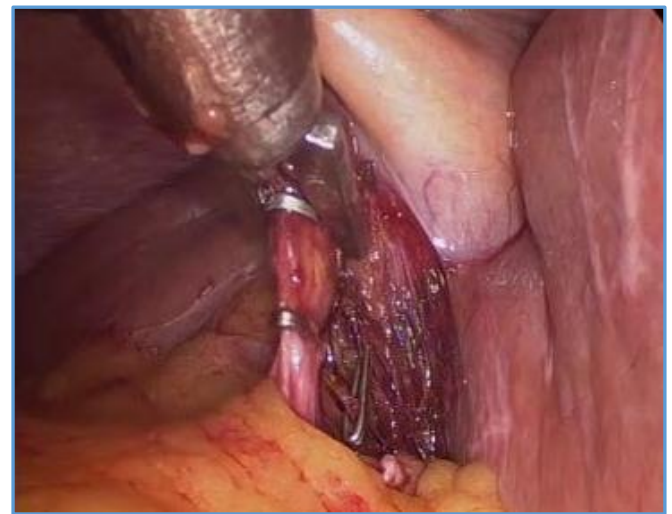

Figure 1. Calot's Triangle

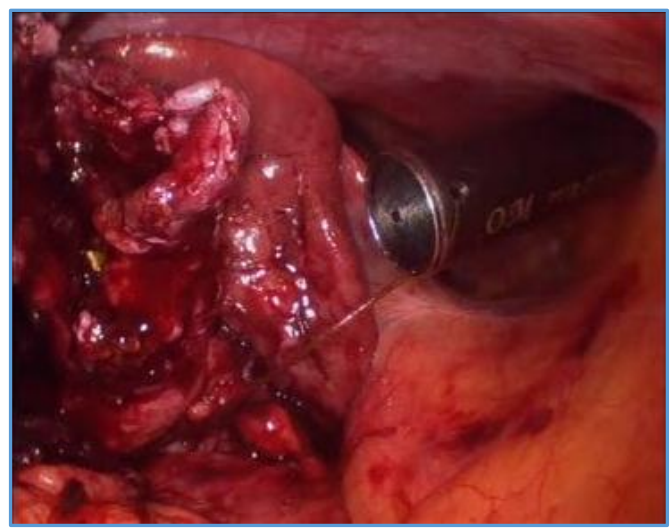

Figure 2 Laparoscopic Subtotal Cholecystectomy

\section{DISCUSSION}

Traditional cholecystectomy is an integral part of every surgical training programme and is performed by most general surgeons. The advent of laparoscopic cholecystectomy has created an excitement and a flurry of activity in the medical community. This study showed that morbidity rate is more with open cholecystectomy than laparoscopic cholecystectomy.

The open procedure is associated with a shorter operating time (LC 60-160 min. and OC 40-135 min.). This is comparable with that of Trondsen ${ }^{1}$ and Porte. ${ }^{2}$ As experience is gained, an operating time of about $50 \mathrm{~min}$. can be achieved, but this increases as other surgeons are trained or more challenging cases are performed. This learning curve represents adapting to operating in the 2-D screen, becoming familiar with the instrumentation and becoming accustomed to the technique. In this study, there were no major complications. There was no peri-operative mortality and no CBD injury. The complications observed were bile leak, stone spillage and blood loss which were found to be comparable in both the groups.

Fewer drains were used in the laparoscopic group, but the difference was not found to be significant. Harris ${ }^{3}$ in his study found similar results, bile leak (LC-2\%, OC-1\%) and bleeding requiring transfusion (LC-1\%, OC-2\%)]. Other studies also reported similar results. ${ }^{2,4}$

The conversion was necessary in 2 patients out of 20 . One patient $(10 \%)$ required conversion due to difficult dissection in view of acute cholecystitis and the other due to slippage of clip applied to cystic artery. Conversion rate was also found to 
be higher in acute cases in other studies (0-45\%).5,6,7

The wound infection rate in this study was found to be less in laparoscopic group (5\% in laparoscopic group versus $25 \%$ in open group). This was due to the reduced size of the incision and lesser wound. This also reduced the need for postoperative antibiotics in the laparoscopy group. Due to the severe wound infection and wound dehiscence, 1 patient in the OC group developed incisional hernia in the followup period. Harris $^{3}$ also noted 1 wound infection in 100 OC patients and 0 in LC group.

Use of minimally invasive techniques in elective surgeries was associated with a reduced inflammatory stress response with improved pulmonary function and less hypoxia.8,9 The VAS was significantly less for LC group. Kum ${ }^{10}$ also found a mean VAS score of $3.8 \mathrm{v} / \mathrm{s} 7.7$ between LC and OC.

The pain duration (median 2 days for LC and median 4 days for OC patients; $p=0.001$ ) and the duration of analgesics used (median 3 days for LC and median 5 days for OC patients; $\mathrm{p}=0.016$ ) also were significantly less in laparoscopic group patients. This was due to the lesser incision size in LC.

In this study, patients who underwent LC were started with oral feeds at duration of 6-8 hours postop compared to 12-36 hours in OC group. The difference was not found to be statistically significant. The two most beneficial aspects of LC were the short hospital stay and the rapid recovery ${ }^{11}$. In this study, the median duration of hospital stay was 4 days for LC group and 7 days for OC group. The difference was found to be statistically significant $(p=0.001) . P^{2}$ Porte $^{2}$, Trondsen $^{1}$ and Lujan ${ }^{6}$ also found similar results.

The time taken to return to normal work was found to be more in OC (median 5 days) compared to LC (median 8 days). It is comparable to Schietroma ${ }^{12}$ who found the time taken was 4.4 days for LC and 7.6 days for OC patients. Compared to OC, the cosmetic outcome was found to be acceptable in 4 of LC patients and 6 of OC patients. While 16 of LC patients were satisfied with the scar of the operation, 14 of OC patients did not accept the surgical scar and deemed it ugly.

The cost was found to be more in LC patients compared to OC patients, but the difference was not found to be statistically significant in this study. The cost of laparoscopy operation was overcome by other costs of open procedure namely increased expenditure on the analgesics, antibiotics, number of dressing changes and the loss of working hours. This was in concordance with other studies.

\section{CONCLUSIONS}

Laparoscopic cholecystectomy is a considerable advancement in the treatment of gall bladder disease. The advantages of laparoscopic cholecystectomy are several-

- Technically, the dissection of the cystic artery and cystic duct is very precise and bleeding is easily controlled with less peri operative blood loss.

- LC is associated with less chances of wound infection and there is no risk of wound dehiscence.

- The antibiotic usage in LC is comparatively lesser than that of OC.
- The degree of postoperative pain and its duration is less.

- The amount of analgesic requirement is less in LC.

- LC patients tolerate oral feeds earlier and are mobilised faster.

- The duration of hospital stay is less and patients can be discharged quickly from the hospital.

- Patients of LC group can resume their work earlier.

- The cosmetic advantage in LC is obvious.

- LC is associated with significant financial saving to the patient.

- The only disadvantage of the laparoscopic cholecystectomy over the open procedure is the duration of operating time which is significantly longer.

\section{REFERENCES}

1. Trondsen E, Riertsen O, Anderson OK, et al. Laparoscopic and open cholecystectomy: a prospective randomized study. Eur J Surg 1993;159(4):217-22.

2. Porte RJ, De Vries BC. Laparoscopic versus open cholecystectomy: a prospective matched-cohort study. HPB Surg 1996;9(2):71-5.

3. Harris BC. Retrospective comparison of outcome of 100 consecutive open cholecystectomies and 100 consecutive laparoscopic cholecystectomies. South Med J 1993;86(9):993-6.

4. Hardy KJ, Miller H, Fletcher DR, et al. An evaluation of laparoscopic versus open cholecystectomy. Med J Aug 1994;160(2):58-62.

5. Eldar S, Sabo E, Nash E, et al. Laparoscopic versus open cholecystectomy in acute cholecystitis. Surg Laparosc Endosc 1997;7(5):407-14.

6. Lujan JA, Parrilla P, Robles R, et al. Laparoscopic cholecystectomy versus open cholecystectomy in the treatment of acute cholecystitis: a prospective study. Arch Surg 1998;133(2):173-5.

7. Koperna T, Kisser M, Schulz F. Laparoscopic versus open treatment of patients with acute cholecystitis. Hepatogastroenterology 1999;46(26):753-7.

8. Williams MD, Sulentich SM, Murr PC. Laparoscopic cholecystectomy produces less postoperative restriction of pulmonary function than open cholecystectomy. Surg Endosc 1993;7(6):489-92.

9. Farrow HC, Fletcher DR, Jones RM. The morbidity of surgical access: a study of open v/s laparoscopic cholecystectomy. Aust NZJ Surg 1993;63(12):952-4.

10. Kum CK, Wong CW, Goh PM, et al. Comparative study of pain level and analgesic requirement after laparoscopic and open cholecystectomy. Surg Laparosc Endosc 1994;4(2):139-41.

11. Attwood SE, Hill AD, Mealy $\mathrm{K}$, et al. A prospective comparison of laparoscopic cholecystectomy versus open cholecystectomy. Ann R Coll Surg Engl 1992;74(6):397400.

12. Schietroma M, Carlei F, Liakos C, et al. Laparoscopic versus open cholecystectomy: an analysis of clinical and financial aspects. Panminerva Med 2001;43(4):239-42. 